\title{
Salvage Technique for Intraoperative Hemorrhage during Laparoscopic Resection of Large Pheochromocytoma: A Case Report and Literature Review
}

\author{
${ }^{1}$ Daniel JK Lee, ${ }^{2}$ Yen P Tan, ${ }^{3}$ Reyaz M Singaporewalla
}

\begin{abstract}
Aim: We described the use of a hand-port assisted laparoscopic adrenalectomy for excising a large $10 \mathrm{~cm}$ vascular left adrenal pheochromocytoma. The useful technical tips and important pitfalls to avoid for a successful outcome are discussed in this article.

Introduction: A 64-year-old man who was investigated for microalbuminuria was found to have a $10-\mathrm{cm}$ left adrenal mass. Blood investigation and imaging confirmed it to be a pheochromocytoma.
\end{abstract}

Case report: Initial mobilization of the adrenal mass was performed laparoscopically using two 5-mm ports in the epigastric. While dissecting the inferomedial pedicle, the aberrant adrenal vessel was injured and resulted in torrential bleeding. A gelport for hand assistance was inserted as a salvage approach for hemostasis.

Conclusion: Hand-port assisted laparoscopic adrenalectomy is a very practical and easy-to-adopt technique that preserves the minimally invasive surgical advantages in patients with large adrenal masses.

Clinical significance: We advocate the use of hand-assisted laparoscopic adrenalectomy technique for complex pheochromocytoma as an alternative for surgeons with vast experience in laparoscopic adrenalectomy.

Keywords: Adrenalectomy, Hand-assisted, Laparoscopic hand-assisted, Laparoscopic hand-assisted adrenalectomy, Large pheochromocytoma.

How to cite this article: Lee DJK, Tan YP, Singaporewalla RM. Salvage Technique for Intraoperative Hemorrhage during Laparoscopic Resection of Large Pheochromocytoma: A Case Report and Literature Review. World J Endoc Surg 2017;9(1):27-31.

Source of support: Nil

Conflict of interest: None

\section{INTRODUCTION}

In this era of minimally invasive surgery, laparoscopic adrenalectomy has become the gold standard for

\footnotetext{
${ }^{1}$ Surgeon, ${ }^{2}$ Resident, ${ }^{3}$ Consultant Surgeon

${ }^{1,2}$ Department of General Surgery, Khoo Teck Puat Hospital Yishun, Singapore

${ }^{3}$ Department of Endocrine Surgery, Khoo Teck Puat Hospital Yishun, Singapore

Corresponding Author: Daniel JK Lee, Surgeon, Department of General Surgery, Khoo Teck Puat Hospital, Yishun, Singapore Phone: +6590273745, e-mail: daniel79jk@gmail.com
}

removing most adrenal lesions. Both the safety and feasibility aspects have been proven along with undisputed postoperative benefits demonstrated over open approach. ${ }^{1-3}$ However, it is sometimes not technically feasible or safe for large, vascular, or suspicious adrenal masses. Successful attempts in laparoscopic approach for large adrenal tumors have only been reported in small case series. ${ }^{4-6}$ There is still no consensus on the maximum size of adrenal tumors that can be removed by laparoscopic approach; however, sizes $>7.5 \mathrm{~cm}$ have been shown to be independent of predictive factors for longer operating times, more blood loss, longer hospital stay, and a higher conversion rate to open surgery. ${ }^{7-9}$

When operating on adrenal tumors, we believe that the approach should be as minimally invasive as possible to minimize postoperative morbidity as long as the surgery does not have added adverse effects. Handassisted laparoscopic adrenalectomy offers this alternative approach for large and complex adrenal tumors where open procedure would otherwise be contemplated. We described below the use of a minimally invasive hand port-assisted laparoscopic adrenalectomy for excising a large $10-\mathrm{cm}$ vascular left adrenal pheochromocytoma. The useful technical tips and important pitfalls to avoid for a successful outcome are discussed.

\section{CASE REPORT}

A 64-year-old Chinese gentleman, with a background history of type II diabetes and hypertension, presented to polyclinic asymptomatic with microalbuminuria on his routine urine checkup. Ultrasound kidneys revealed an incidental left adrenal mass measuring $10 \mathrm{~cm}$ (Fig. 1). He subsequently underwent endocrine work-up and was diagnosed to have a left pheochromocytoma with raised levels of the 24-hour urine normetanephrine and noradrenaline. Computed tomography (CT) of adrenals (Figs 2A and B) showed a heterogeneous, hypervascular left adrenal mass measuring $10 \mathrm{~cm}$ with no features of invasion to surrounding organs. No locoregional lymphadenopathy or metastatic lesion was seen. He was scheduled for an elective laparoscopic keep-inview hand-assisted left adrenalectomy. Preoperatively, he was optimized with alpha-blockade phenoxybenzamine 


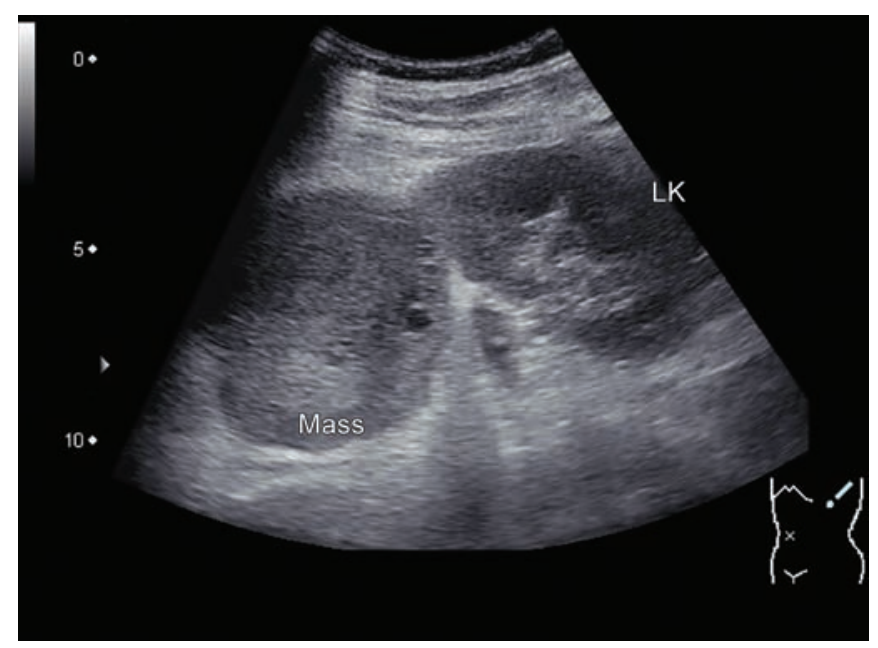

Fig. 1: Ultrasound left kidney with large adrenal mass

for 2 weeks and beta-blockers for 3 days prior to surgery. He was admitted 1 day prior to operation date for IV fluid hydration and high sodium diet. Surgery was planned with postoperative surgical intensive care unit (ICU) support.

Intraoperatively, patient was placed in a right lateral decubitus position, flexed at the waist. A 10-mm left subcostal access just anterior to the mid-axillary line was made for camera port. Three working trocars were inserted under direct vision: $2 \times 12 \mathrm{~mm}$ ports at the posterior of the left mid-axillary line and $1 \times 5 \mathrm{~mm}$ port at the left anterior axillary line.

We began by mobilizing the splenic flexure and spleen, during which engorged vessels entering the adrenal mass were encountered along the lateral abdominal wall. These vessels, along with the splenorenal ligaments, were carefully divided with ultrasonic energy device, and the spleen was medialized. Upon dividing perirenal fat, a large mass of convoluted vessels was found enveloping the adrenal gland (Fig. 3). Careful dissection was carried out to mobilize the tumor from the posterolateral surface and upper pole of the left kidney. We used a combination of ultrasonic energy device and laparoscopic diathermy to aid in dissection. Feeding vessels were prophylactically clipped prior to division. During dissection of the inferomedial pedicle, the medial adrenal artery was injured and resulted in brisk and torrential bleeding. We immediately placed packs in and had the assistant compress the bleeding site. Simultaneously, the surgeon proceeded to make a horizontal incision connecting the two ports at right flank to insert a gel-port for hand-assisted approach. Homeostasis was achieved and hand-assisted laparoscopic dissection was performed to complete full mobilization of the left adrenal tumor. This incision was later used as the specimen extraction site.
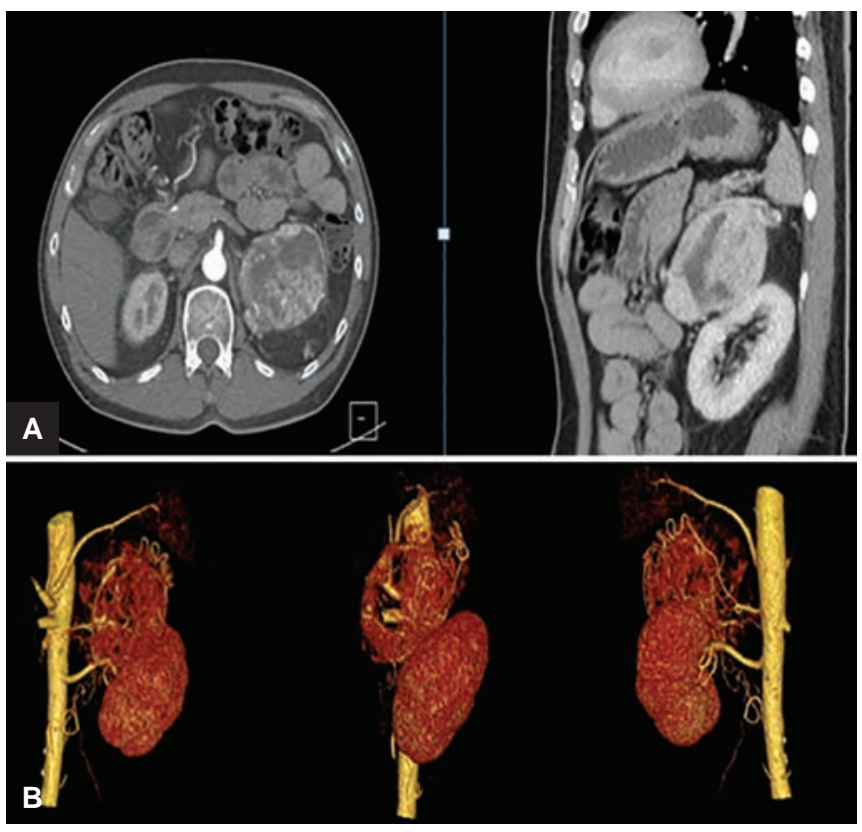

Figs 2A and B: Computed tomography adrenals: (A) Large, hypervascular adrenal mass measuring $10 \mathrm{~cm}$ in diameter; and (B) CT 3D reconstruction. Multiple and tortuous arterial supplies to left adrenal gland demonstrated. Left medial adrenal artery arising directly from the aorta

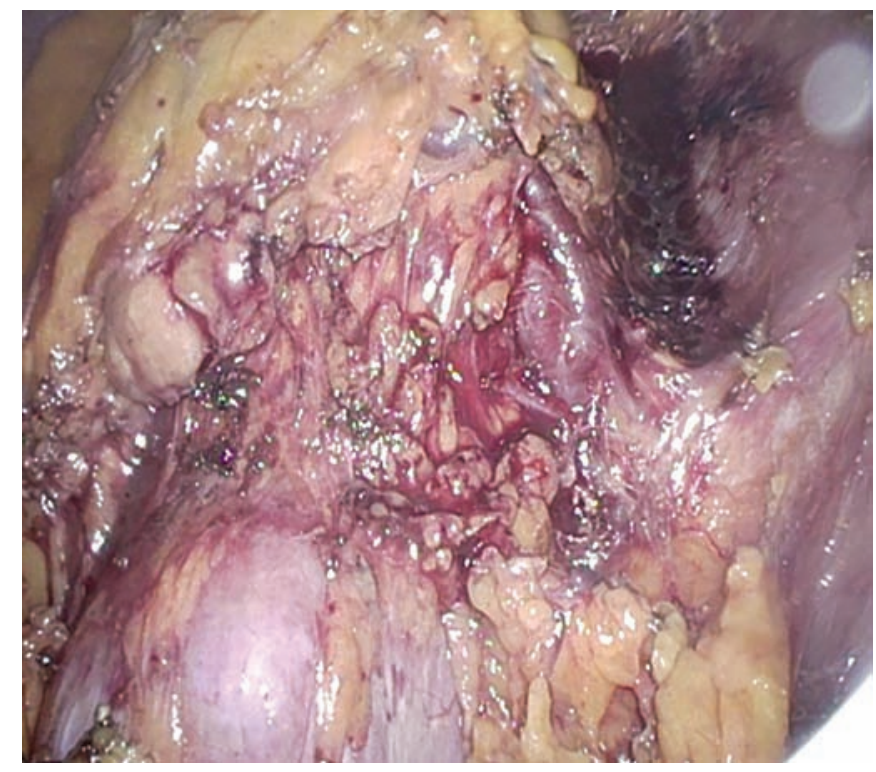

Fig. 3: Mass of convoluted vessels covering the adrenal mass

Postoperatively, patient was monitored in surgical ICU to maintain hemodynamic stability and to avoid hypoglycemia. He was discharged well on postoperative day 4. Histopathology examination confirmed a 10-cm left adrenal pheochromocytoma with $\mathrm{R} 0$ resection (Fig. 4).

\section{DISCUSSION}

One of the main challenges faced when operating on pheochromocytomas laparoscopically, let alone a large adrenal tumor, such as the one in this current case is hemodynamic instability. Hemodynamic shifts have 


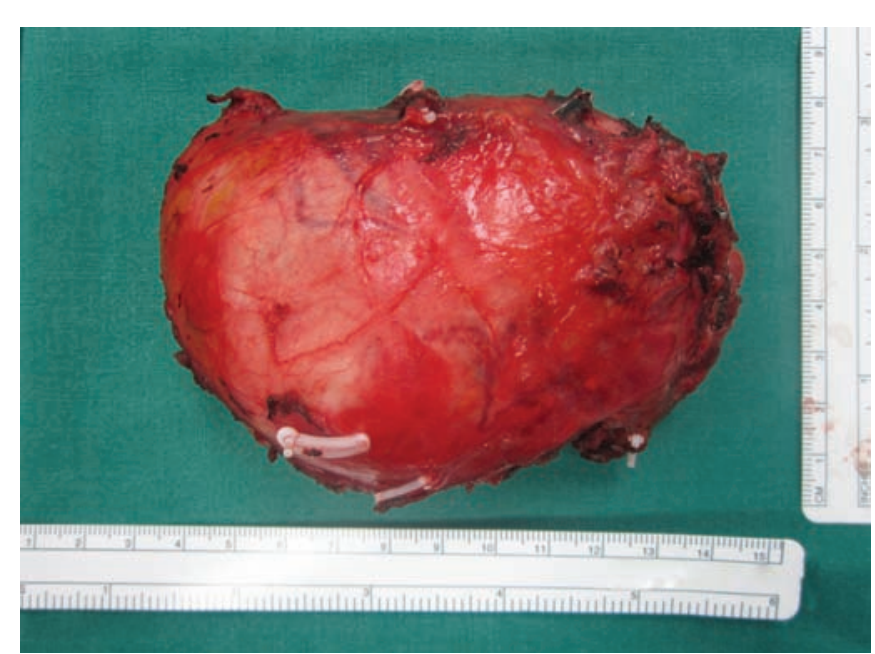

Fig. 4: Final specimen removed intact

been observed as a result of pneumoperitoneum, ${ }^{10}$ direct manipulation of the adrenal gland, ${ }_{11}^{11}$ or from significant blood loss. $\mathrm{CO}_{2}$ pneumoperitoneum can result in respiratory acidosis, hypercapnia, and cardiovascular instability, all of which pheochromocytoma patients are susceptible to. ${ }^{12}$ However, Gagner et $\mathrm{a}^{13}$ had safely demonstrated the use of laparoscopic adrenalectomy in pheochromocytomas. Currently, we know that the pathology of pheochromocytoma alone does not increase laparoscopicassociated morbidity. ${ }^{14}$ It is the additional effect of the catecholamine surge of the gland during manipulation, which can occur both in open and laparoscopic approach, ${ }^{15,16}$ that poses a significant challenge to the anesthetist to control hemodynamic stability. The key to mitigate this risk is adequate adrenergic blockade and preoperative vascular expansion. ${ }^{17,18}$ Shen et al ${ }^{7}$ who analyzed their series of 261 laparoscopic adrenalectomies found that patients with large pheochromocytomas $(>5 \mathrm{~cm})$ and had demonstrated an unstable preoperative clinical course are more likely to end up with conversion to open or hand-assisted approach. This emphasizes the fact that when planning for laparoscopic resection of large and complex adrenal tumors, a concerted effort with the endocrinologist and anesthetist for preoperative preparation is of utmost importance to ensure a good outcome.

While laparoscopic adrenalectomy for pheochromocytoma has been proven to be safe and effective, the applicability of minimally invasive approach on such large tumors is still questionable. When the laparoscopic approach is used for larger-sized adrenal tumors, there is a high risk of conversion to open surgery and surgeryrelated morbidities. ${ }^{19}$ Besides that, in a large adrenal tumor, we also have to be cautious that it could be potentially malignant. Various case series have reported the incidence of between 35 and $98 \%$ of malignancy in adrenal tumors $>5 \mathrm{~cm}$ in size. ${ }^{20}$ Laparoscopic approach in malignant tumors may compromise resection margin due to its local invasion to surrounding structures or cause tumor spillage during dissection, especially in the hands of less experienced surgeons. Therefore, it is necessary for the operating surgeon to carefully evaluate preoperative images (i.e., CT, magnetic resonance imaging, or Metaiodobenzylguanidine scans) for any features of local invasion and adjacent lymphadenopathy. In our case, the tumor showed no features of local invasion. It was well encapsulated but all within a convoluted mass of blood vessels (Fig. 2A). These features do not preclude the patient for a laparoscopic approach, but it did pose an increased risk of intraoperative blood loss. Adrenal artery embolization can be performed in such a situation to reduce tumor bulk and its vascularity. ${ }^{21}$ Unfortunately, it was deemed high risk for collateral damage; hence, selective angio-embolization was not performed.

Laparoscopic dissection of a pheochromocytoma can be technically challenging, especially in a highly vascularized tumor. Large tumors usually have numerous retroperitoneal feeding vessels that require meticulous dissection. Moreover, pheochromocytomas tend to be associated with a local desmoplastic reaction, creating adhesions and fibrosis. These factors can cause increased blood loss and are often associated with longer operative time. Despite these limitations, many reports have shown increased blood loss or prolonged operative time that did not translate into increased morbidity. ${ }^{22-24}$ It is therefore, not unreasonable for us to proceed with the minimally invasive approach for this particular case. The initial dissection around the tumor was performed laparoscopically. To minimize blood loss, we used a combination of energy device and laparoscopic diathermy to aid in dissection, and prophylactically clipped over the feeding vessels prior to the division of tissue. In contrary to common belief, we found that the use of laparoscopic hook diathermy in dissection on highly vascularized tumors can sometimes prove to be advantageous. It allows precise dissection along the thin tissue plane and exposes the underlying blood vessels without causing collateral damage. However, this method is tedious and hence, resulted in prolonged operative duration.

We, as well as many, believe that the transperitoneal approach offers more familiar anatomic landmarks to general or endocrine surgeons for orientation than those described in extraperitoneal approaches. ${ }^{25,26}$ Apart from that, the transperitoneal approach also allows us to gain easier direct access to the adrenal vein in order for us to ligate it prior to manipulation of the gland. Unfortunately, this complex tumor was covered with multiple tortuous feeding vessels, preventing us from isolating the adrenal vein first. This is where the hand-assisted technique using 
a gel-port successfully gave us a "helping hand" here. The gel-port allowed insertion of the surgeon's left hand, without loss of pneumoperitoneum, and therefore, gave additional tactile sensation for dissection and isolation of the major vessels from the retroperitoneum supplying the tumor. It also facilitated a much more rapid and direct approach to isolate the vascular inflow and outflow using temporary hemostasis of the inevitable oozing that occurs from the tumor surface until it was completely excised. These were all performed while preserving the spatial orientation and optimal view of the retroperitoneal structures seen through the laparoscope. In our experience, hand-assisted laparoscopic approach is frequently used as a salvage maneuver when dealing with complex tumors before converting it to open procedure.

When the major accidental bleeding occurred, by having one hand inside the abdomen we managed to control it immediately by applying direct digital pressure and further dealt with using harmonic shears, diathermy, and clips. As we were approaching the pedicles, we could carefully palpate for arterial pulsation and therefore, accurately locate the appropriate one. The fingers are ideal tools used to isolate the pedicle for vascular control and transection. Further dissection was completed fairly quickly by using the hand to flip the tumor off to one side while maintaining counter traction with the index finger to expose the dissection plane. We believe that without the hand-assisted approach, many would have converted to the open tactic when faced with critical situations, resulting in a large incision.

Bennett and Ray ${ }^{27}$ were the first to report the successful use of transperitoneal hand-assisted laparoscopic adrenalectomy in three cases of small adrenal tumors (1-3.5 cm in diameter). They concluded that the handassisted approach is technically feasible and reported comparable outcomes with those seen in the laparoscopiconly technique. Gel-port requires only a small incision $(7 \mathrm{~cm})$, therefore, resulting in minimal postoperative pain. In recent literatures, laparoscopic adrenalectomy for large pheochromocytomas has been reported to be associated with faster postoperative recovery when compared with open adrenalectomy. Average length of hospital stay is reported to be of 4 days for laparoscopic approach, compared to that of 9 days in the open group. ${ }^{28,29}$ In our current case, patient was discharged home well on postoperative day 4 . Hand-assisted adrenalectomy would therefore, still represent a significant advantage over the open technique.

\section{CONCLUSION}

The hand-port assisted laparoscopic adrenalectomy is a very practical, feasible, and easy-to-adopt technique that preserves the minimally invasive surgical advantages in patients with large and challenging adrenal masses. It also facilitates the laparoscopic procedure without adding significant trauma. This case has demonstrated that large pheochromocytomas can be removed safely by minimally invasive approach with careful preoperative preparation and full understanding of hand-assisted technique, used as a salvage maneuver, by the operating surgeon.

\section{CLINICAL SIGNIFICANCE}

The use of hand-port assisted technique is described as a salvage approach for hemostasis while performing laparoscopic dissection of a large and vascular pheochromocytoma. The gel-port allowed insertion of surgeon's left hand giving additional tactile sensation for dissection and isolation of the major vessels arising from the retroperitoneum. This helps to facilitate faster and more direct approach to achieve hemostasis, yet preserving the minimally invasive surgical advantages. This technique is easy to adopt especially for surgeons with vast experiences in laparoscopic adrenalectomy.

\section{REFERENCES}

1. Gagner M, Pomp A, Heniford BT, Pharand D, Lacroix A. Laparoscopic adrenalectomy: lessons learned from 100 consecutive procedures. Ann Surg 1997 Sep;226(3):238-246.

2. Hallfeldt KK, Mussack T, Trupka A, Hohenbleicher F, Schmidbauer S. Laparoscopic lateral adrenalectomy versus open posterior adrenalectomy for the treatment of benign adrenal tumors. Surg Endosc 2003 Feb;17(2):264-267.

3. Kang T, Gridley A, Richardson WS. Long-term outcomes of laparoscopic adrenalectomy for adrenal masses. J Laparoendosc Adv Surg Tech A 2015 Mar;25(3):182-186.

4. Indupur RR, Nerli RB, Reddy MN, Siddappa SN, Thakkar R. Laparoscopic adrenalectomy for large pheochromocytoma. BJU Int 2007 Nov;100(5):1126-1129.

5. Ramacciato G, Mercantini P, La Torre M, Di Benedetto F, Ercolani G, Ravaioli M, Piccoli M, Melotti G. Is laparoscopic adrenalectomy safe and effective for adrenal masses larger than $7 \mathrm{~cm}$ ? Surg Endosc 2008 Feb;22(2):516-521.

6. Zografos GN, Farfaras A, Vasiliadis G, Pappa T, Aggeli C, Vassilatou E, Kaltsas G, Piaditis G. Laparoscopic resection of large adrenal tumors. JSLS 2010 Jul-Sep;14(3):364-368.

7. Shen WT, Kebebew E, Clark OH, Duh QY. Reasons for conversion from laparoscopic to open or hand-assisted adrenalectomy: review of 261 laparoscopic adrenalectomies from 1993 to 2003. World J Surg 2004 Nov;28(11):1176-1179.

8. Castillo OA, Vitagliano G, Secin FP, Kerkebe M, Arellano L. Laparoscopic adrenalectomy for adrenal masses: does size matter? Urology 2008 Jun;71(6):1138-1141.

9. Parnaby CN, Chong PS, Chisholm L, Farrow J, Connell JM, O'Dwyer PJ. The role of laparoscopic adrenalectomy for adrenal tumours of $6 \mathrm{~cm}$ or greater. Surg Endosc 2008 Mar;22(3): 617-621.

10. Mann C, Millat B, Boccara G, Atger J, Colson P. Tolerance of laparoscopy for resection of phaeochromocytoma. $\mathrm{Br}$ J Anaesth 1996 Dec;77(6):795-797. 
11. Janetschek G, Neumann HP. Laparoscopic surgery for pheochromocytoma. Urol Clin North Am 2001 Feb;28(1):97-105.

12. Fernández-Cruz L, Sáenz A, Taurá P, Sabater L, Astudillo E, Fontanals J. Helium and carbon dioxide pneumoperitoneum in patients with pheochromocytoma undergoing laparoscopic adrenalectomy. World J Surg 1998 Dec;22(12): 1250-1255.

13. Gagner M, Lacroix A, Bolté E. Laparoscopic adrenalectomy in Cushing's syndrome and pheochromocytoma. N Engl J Med 1992 Oct1;327(14):1033.

14. Nau P, Demyttenaere S, Muscarella P, Narula V, Hazey JW, Ellison EC, Melvin WS. Pheochromocytoma does not increase risk in laparoscopic adrenalectomy. Surg Endosc 2010 Nov;24(11):2760-2764.

15. Joris JL, Hamoir EE, Hartstein GM, Meurisse MR, Hubert BM, Charlier CJ, Lamy ML. Hemodynamic changes and catecholamine release during laparoscopic adrenalectomy for pheochromocytoma. Anesth Analg 1999 Jan;88(1):16-21.

16. Sesay M, Tauzin-Fin P, Gosse P, Ballanger P, Maurette P. Realtime heart rate variability and its correlation with plasma catecholamines during laparoscopic adrenal pheochromocytoma surgery. Anesth Analg 2008 Jan;106(1):164-170.

17. Pacak K. Preoperative management of the pheochromocytoma patient. J Clin Endocrinol Metab 2007 Nov;92(11): 4069-4079.

18. van der Horst-Schrivers AN, Kerstens MN, Wolffenbuttel BH. Preoperative pharmacological management of phaeochromocytoma. Neth J Med 2006 Sep;64(8):290-295.

19. Bittner JG 4th, Gershuni VM, Matthews BD, Moley JF, Brunt LM. Risk factors affecting operative approach, conversion, and morbidity for adrenalectomy: a single-institution series of 402 patients. Surg Endosc 2013 Jul;27(7):2342-2350.

20. Kebebew E, Siperstein AE, Clark OH, Duh QY. Results of laparoscopic adrenalectomy for suspected and unsuspected malignant adrenal neoplasms. Arch Surg 2002 Aug;137(8): 948-951.

21. O'Keeffe FN, Carrasco CH, Charnsangavej C, Richli WR, Wallace S. Arterial embolization of adrenal tumors: results in nine cases. AJR Am J Roentgenol 1988 Oct;151(4):819-822.

22. Kalady MF, McKinlay R, Olson Jr JA, Pinheiro J, Lagoo S, Park A, Eubanks WS. Laparoscopic adrenalectomy for pheochromocytoma. A comparison to aldosteronoma and incidentaloma. Surg Endosc 2004 Apr;18(4):621-625.

23. Henry JF, Defechereux TH, Gramatica LO, Raffaelli M. Should laparoscopic approach be proposed for large and/or potentially malignant adrenal tumors? Langenbeck Arch Surg 1999 Aug;384(4):366-369.

24. Hobart MG, Gill IS, Schweizer D, Sung GT, Bravo EL. Laparoscopic adrenalectomy for large-volume $(\geq 5 \mathrm{~cm})$ adrenal masses. J Endourol 2000 Mar;14(2):149-154.

25. Constantinides VA, Christakis I, Touska P, Meeran K, Palazzo F. Retroperitoneoscopic or laparoscopic adrenalectomy? A single-centre UK experience. Surg Endosc 2013 Nov;27(11):4147-4152.

26. Goonewardene SS, Brown M, Challacombe BJ. Adrenalectomy: a retroperitoneal procedure. BJU Int 2016 May;117(5): 718-719.

27. Bennett IC, Ray M. Hand assisted laparoscopic adrenalectomy: an alternative minimal invasive surgical technique for the adrenal gland. ANZ J Surg 2002 Nov;72(11):801-805.

28. Agrusa A, Romano G, Frazzetta G, Chianetta D, Sorce V, Di Buono G, Gulotta G. Laparoscopic adrenalectomy for large adrenal masses: single team experience. Int J Surg 2014 Aug;12 (Supp 1):S72-74.

29. Wang W, Li P, Wang Y, Wang Y, Ma Z, Wang G, Gao J, Zhou H. Effectiveness and safety of laparoscopic adrenalectomy of large pheochromocytoma: a prospective, nonrandomized, controlled study. Am J Surg 2015 Aug;210(2):230-235. 